\title{
Determination of the main solid-state form of albendazole in bulk drug, employing Raman spectroscopy coupled to multivariate analysis
}

\author{
Natalia L. Calvo a , Juan M. Arias ${ }^{\mathrm{b}}$, Aída Ben Altabef ${ }^{\mathrm{b}}$, Rubén M. Maggio ${ }^{\mathrm{a}, *}$, \\ Teodoro S. Kaufman ${ }^{\mathrm{a}, *}$ \\ a Área de Análisis de Medicamentos, Facultad de Ciencias Bioquímicas y Farmacéuticas, Universidad Nacional de Rosario e Instituto de Química Rosario \\ (IQUIR, CONICET-UNR), Suipacha 531, Rosario S2002LRK, Argentina \\ ${ }^{\mathrm{b}}$ Instituto de Química Física, Facultad de Bioquímica, Química y Farmacia, Universidad Nacional de Tucumán (INQUINOA, CONICET-UNT), San Lorenzo 456, \\ Tucumán T4000CAN, Argentina
}

\section{A R T I C L E I N F O}

\section{Article history:}

Received 16 May 2016

Received in revised form 7 July 2016

Accepted 8 July 2016

Available online 10 July 2016

\section{Keywords:}

Albendazole

Solid state forms

Raman spectroscopy

Chemometrics

PLS

\begin{abstract}
A B S T R A C T
Albendazole (ALB) is a broad-spectrum anthelmintic, which exhibits two solid-state forms (Forms I and II). The Form I is the metastable crystal at room temperature, while Form II is the stable one. Because the drug has poor aqueous solubility and Form II is less soluble than Form I, it is desirable to have a method to assess the solid-state form of the drug employed for manufacturing purposes.

Therefore, a Partial Least Squares (PLS) model was developed for the determination of Form I of ALB in its mixtures with Form II. For model development, both solid-state forms of ALB were prepared and characterized by microscopic (optical and with normal and polarized light), thermal (DSC) and spectroscopic (ATR-FTIR, Raman) techniques. Mixtures of solids in different ratios were prepared by weighing and mechanical mixing of the components.

Their Raman spectra were acquired, and subjected to peak smoothing, normalization, standard normal variate correction and de-trending, before performing the PLS calculations. The optimal spectral region $\left(1396-1280 \mathrm{~cm}^{-1}\right)$ and number of latent variables $(\mathrm{LV}=3)$ were obtained employing a moving window of variable size strategy.

The method was internally validated by means of the leave one out procedure, providing satisfactory statistics $\left(r^{2}=0.9729\right.$ and RMSD $=5.6 \%$ ) and figures of merit (LOD = 9.4\% and MDDC $\left.=1.4\right)$. Furthermore, the method's performance was also evaluated by analysis of two validation sets. Validation set I was used for assessment of linearity and range and Validation set II, to demonstrate accuracy and precision ( Recovery $=101.4 \%$ and $\mathrm{RSD}=2.8 \%$ ). Additionally, a third set of spiked commercial samples was evaluated, exhibiting excellent recoveries ( $94.2 \pm 6.4 \%)$.

The results suggest that the combination of Raman spectroscopy with multivariate analysis could be applied to the assessment of the main crystal form and its quantitation in samples of ALB bulk drug, in the routine quality control laboratory.
\end{abstract}

(c) 2016 Elsevier B.V. All rights reserved.

\section{Introduction}

Albendazole (ALB, methyl [5-(propylthio)-1- $H$-benzimidazol2-yl] carbamate) is a wide spectrum benzimidazole-type antihelmintic agent, which is effective in nematode (i.e. Ascaris lumbricoides, Ancylostoma duodenalis, Trichuris trichiur and Necator americanus), cestode (i.e. Taenia saginata and T. solium) and trematode (i.e. Schistosoma mansoni and S. haematobium) infections of

\footnotetext{
* Corresponding authors.

E-mail addresses: maggio@iquir-conicet.gov.ar (R.M. Maggio), kaufman@iquir-conicet.gov.ar (T.S. Kaufman).
}

the gastrointestinal tract. ALB is also indicated for treatment of cystic hydatidosis caused by Echinococcus granulosus [1] and it is worldwide used in campaigns against filariasis [2], including those managed by the World Health Organization (WHO).

Because of its wide spectrum of activity, pharmacological profile, good tolerance and low cost, ALB is also a very important component of the veterinary pharmacological arsenal, especially for big and small ruminants [3], and companion animals [4]. ALB is included in the WHO list of essential medicines [5]; it is also official in several well-recognized Pharmacopoeias, where infrared absorption is commonly employed as one of its identification tests [6-9]. 
Some molecules hold the ability to exist as two or more phases in the solid substance, characterized by different arrangements or molecular conformations [10]. Hence, different solid-state forms may have different physical and chemical properties. These differences can have direct impact on the processing of the active principles and the quality of the finished drug products, including their stability, dissolution and bioavailability [11]. As part of the continuous evolution toward stricter regulations, it is observed an increasing interest of official regulation bodies in the development of analytical methodologies for the detection and quantitation of solid-state forms in mixtures.

Recently, it has been conclusively demonstrated that ALB exhibits two enantiotropic solid-state forms (Forms I and II), bearing a tautomeric relationship [12]. Chattah et al. have studied these forms by solid-state NMR, confirming that they are desmotropes [13]. The term desmotropy applies to a substance that has tautomers, which can be isolated (crystallized) as separate stable forms. The phenomenon is also known as tautomeric polymorphism. Relatively few and scattered examples of desmotropy have been published, most of them involving heterocycles [14,15].

The Form I of ALB is the most frequently available, whilst Form II can be obtained by concentration of a methanolic solution of ALB, where the drug is sparingly soluble; both forms demonstrated to be physically stable $[12,16]$. However, the solid state landscape of ALB could become more complicated, since the presence of up to five phases in solid ALB has been recently described based on Rietveld analysis of powder X-ray diffraction data [17].

It has been conjectured that the structural differences that could be associated with ALB (Fig. 1A) having different solid-state forms are of at least four possible types, including (1) tautomeric; (2) conformational, of either one or both side-chains; (3) molecular disorder and (4) different hydrogen bonding arrangements. Moreover, combinations of these should not be discarded [12].

The powder X-ray diffraction, DSC (differential scanning calorimetry) and melting point data reported in the literature for different sources of the drug [18-21] suggest that both, Form I and Form II, and perhaps their mixtures, are available in the market and have been concomitantly used, and that both, drug manufacturers and regulators, have been paying little attention to the solid-state characteristics of ALB. An example of this situation is the proposal of the use of $\mathrm{MeOH}$ as a washing solvent for ALB in a recent patent dealing with the preparation of the active pharmaceutical ingredient (API) [22].

Like other benzimidazoles, ALB exhibits low aqueous solubility $\left(\sim 1.3 \mathrm{mg} \mathrm{l}^{-1}\right)$ [23] and erratic oral bioavailability mainly due to its slow dissolution rate in aqueous media; therefore, minor solubility differences among its solid-state forms may exert an important effect on drug absorption [24]. Since Form I has better aqueous solubility than Form II, being also more soluble in methanol and in $0.1 \mathrm{~N} \mathrm{HCl}$, the former is being assumed the metastable form of ALB at room temperature.

There is an undergoing conflict regarding the assignment of ALB to Class II (low solubility and high permeability) $[16,19]$ or Class IV (low solubility and low permeability) [25] in the biopharmaceutics classification system [26], making ALB a unique case of study and turning crucial the solid-state characterization of the drug substance.

Hence, according to current regulations, it is deemed relevant to unequivocally identify the solid-state form, from which the drug formulation will be prepared [27]. This need has been recognized and the development of new methods based on spectroscopic techniques as means for identifying and limiting solid-state forms of ALB has been recently set as an industrial goal [28].

Raman is one of the most useful spectroscopies for the analysis of active pharmaceutical ingredients, because it is not destructive, affords rapid results and spectra are rich in information. Chemo- metrics methods are increasingly used to empower the analysis of Raman spectroscopic data.

The dimensionality reduction properties of multivariate data analysis techniques turn the association between Raman spectroscopy and chemometrics into a valuable and powerful tool for highlighting minor features, which enables the discrimination among very close compounds or analytes with highly similar spectral signatures. Further, relating spectral information to chemical properties of the analytes, the simultaneous analysis of the whole data set allows the quantification of given compounds in complex systems $[29,30]$.

Therefore, in pursuit of our continuous interest in studying the solid state features of pharmaceutically relevant compounds [31-33], herein we report the development and validation of a Raman-chemometrics approach, useful for identification and quantitation of the different solid-state forms of ALB in bulk drug. Partial Least Squares (PLS) is employed as the chemometrics tool, and the scope and limitations of the method are also explored.

\section{Material and methods}

\subsection{Instrumentation}

Optical microscopy of the crystal forms was carried out with the aid of a Correct optical microscope (Seiwa Optical, Tokyo, Japan), fitted with $10 \times, 40 \times$ and $100 \times$ objectives. Polarized light optical microscopy was carried out with an Ernst Leitz model 350 polarizing microscope (Wetzlar, Germany). Both instruments were equipped with a 5.0 Megapixels Beion CMOS digital camera [Shanghai Beion Medical Technology Co., Ltd., Shanghai, China; resolution $2592 \times 1944(\mathrm{H} \times \mathrm{V})]$.

The calorimetric determinations were performed in a Shimadzu model DSC60 differential scanning calorimeter (Shimadzu Corp., Kyoto, Japan), operating under a constant flow of nitrogen $\left(30 \mathrm{ml} \mathrm{min}^{-1}\right)$. The sample powders $(\sim 1-5 \mathrm{mg})$ were placed in closed aluminum pans perforated with a pinhole to equilibrate pressure from potential expansion of evolved gases or residual solvents, and heated at a rate of $40^{\circ} \mathrm{Cmin}^{-1}$ between 30 and $270^{\circ} \mathrm{C}$. An empty pan was used as a reference.

The FTIR spectra were acquired in a Shimadzu Prestige $21 \mathrm{spec}-$ trometer (Shimadzu Corp., Kyoto, Japan) over a wavenumber range of $4000-600 \mathrm{~cm}^{-1}$. The ATR experiments were carried out with a diamond-based ATR accessory (GladiATR, Pike Technologies, Madison, USA), fitted with a Pike temperature control unit.

The Raman spectra were measured with a Thermo Scientific DXR Raman microscope at room temperature, with the samples placed on gold-coated sample slides. The Raman spectral data were collected using a diode-pump, solid state laser of $532 \mathrm{~nm}\left(\right.$ at $5 \mathrm{~cm}^{-1}$ spectral resolution), a confocal aperture of $25 \mu \mathrm{m}$ pinhole, and a $10 \times$ objective, in the spectral range $3420-100 \mathrm{~cm}^{-1}$. To achieve a proper signal to noise ratio, 30 expositions of 2 s each were accumulated during the measurements, with the laser power maintained at $10 \mathrm{~mW}$. The Raman spectra were individually exported in .txt format for their further processing and analysis.

\subsection{Chemicals}

Two different lots of pharmaceutical grade ALB were used. They were received as kind gifts from the Pilot Plant of Drug Production, School of Biochemical and Pharmaceutical Sciences-UNR. All other chemicals were of analytical grade and were used as received. During the experiments, the APIs were kept in a desiccator, protected from light. 


\subsection{Preparation of the ALB crystal forms}

Both lots of ALB were analyzed, proving to contain only Form I; therefore, they were used as received. A stock amount of Form II was obtained from lot I of ALB according to literature, by dissolving a sample of the bulk drug in methanol and warming at $40^{\circ} \mathrm{C}$ until a clear solution ( $1 \mathrm{mg} \mathrm{ml}^{-1}$ ) was obtained. Then, the solution was filtered and the filtrate was allowed to concentrate spontaneously under ambient conditions until crystallization was complete [12]. During the experiments, Form II of ALB was kept in a desiccator, protected from light.

\subsection{Preparation of mixtures containing different solid-state forms}

In order to develop a quantitative method for the determination of the content of Form I in the commercial API, training and validation sample sets were prepared, containing different mixtures of both solid-state forms.

The pure solid-state forms were separately sieved with an RR1920 Zonitest Vibration system (Rey \& Ronzoni, Buenos Aires, Argentina), fitted with ASTM-certified stainless steel sieves, to a particle size between 50 and 100 mesh, and four groups of samples (Training, Validation I, Validation II and Commercial) were prepared by weighing and mixing the solids. All samples were mixed in a rotatory $\mathrm{Z}$ mixer at $40 \mathrm{rpm}$ for $30 \mathrm{~min}$.

The Training set contained physical mixtures of Form I and Form II, made by weight, ranging from 0 to $100 \%$ ALB Form I, at five levels $(0,20,40,60,80$ and $100 \% w / w)$. Analogously, the Validation I set was made of ALB Form I at five levels (10, 30, 50, 70 and 90\% $w / w)$. Samples of both sets were prepared in triplicate, rendering a total of 18 and 15 samples, respectively.

The Validation II set was prepared in duplicate samples at three levels of Form I (60, 70 and $80 \% w / w)$ in Form II. Finally, the Commercial set of samples was also prepared in duplicate, by spiking ALB lot II (Form I) with Form II, to give mixtures containing 25, 50 and $75 \% w / w$ of Form I. During the experiments, the samples were kept in a desiccator, protected from light.

\subsection{Chemometrics and graphics software}

The computer routines involving spectral data manipulation (normalization, Savitzky-Golay smoothing, variable selection) and the PLS method were run in the Matlab R2010a (Mathworks, Natick, USA) environment. Statistical data analyses and miscellaneous graphics were performed using Origin 8.5 (OriginLab Co., Northampton, USA).

\section{Results and discussion}

\subsection{Characterization of the solid-state forms}

The solid-state Forms I and II of ALB were obtained following the procedures described in Section 2.3. Preparation of ALB crystal forms. The solid-state forms were designated according to Pranzo et al. (Forms I and II) [12], being equivalent to the names ALB I and ALB II coined by the group of Chattah [13]. Their characterization was performed by optical microscopy, DSC, ATR-FTIR spectroscopy and Raman spectroscopy, under standardized measurement conditions of temperature, particle size and amount of sample. The characteristic data of the different forms are collected in Table 1.

When the identity of the crystal forms was ascertained using optical digital microscopy, Form I was observed as small prismatic crystals (Fig. 1B) and Form II appeared as big platelets (Fig. 1C). The characteristic shapes of both forms were in agreement with the literature [12]; additionally, it was noticed that when the crystals were examined under polarized light, Form II showed birefringence (Fig. 1D) [34].

In the DSC analysis, Form I exhibited a single endothermic peak (Fig. 2A) without shoulders, at $214.0^{\circ} \mathrm{C}$, corresponding to its melting point. On the other side, Form II displayed a small endotherm at $155^{\circ} \mathrm{C}$ followed by an exotherm with a peak at $165^{\circ} \mathrm{C}$. According

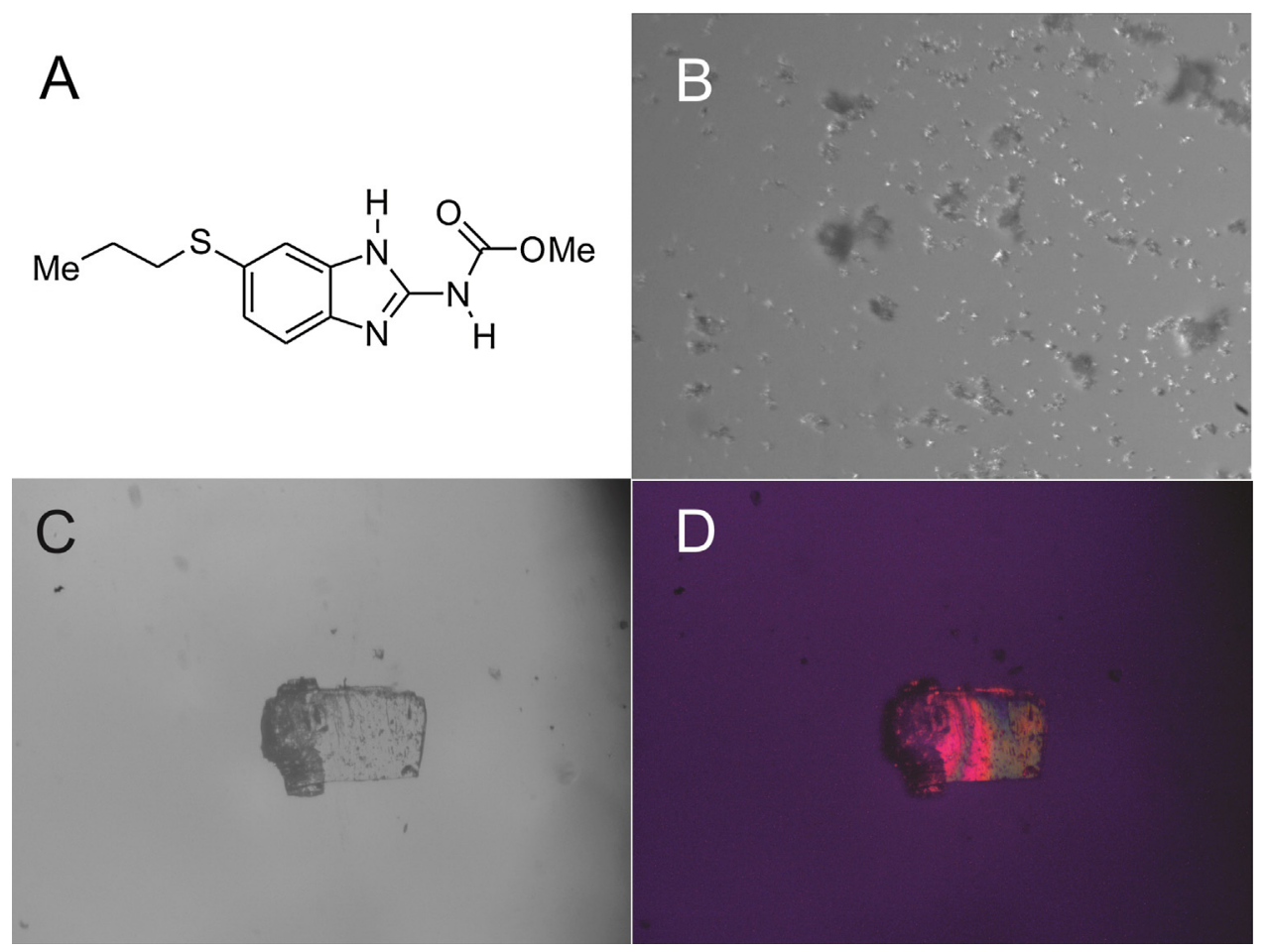

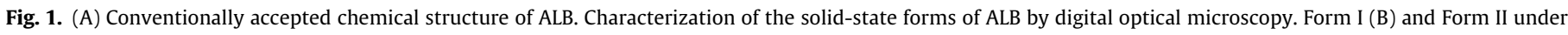
conventional (C) and polarized light (D). 
Table 1

Data summary of the main microscopic, thermal and FTIR features of the different crystal forms of ALB.

\begin{tabular}{|c|c|c|}
\hline Parameter & Form I & Form II \\
\hline Optical microscopy & Small prismatic crystals & Big platelets \\
\hline Polarized light microscopy & No birefringence & Birefringence \\
\hline \multirow[t]{3}{*}{ DSC, ${ }^{\circ} \mathrm{C}$ (observation) } & 214.0 (endotherm) & 155.0 (endotherm) \\
\hline & & 165.0 (exotherm) \\
\hline & & 218.8 (endotherm) \\
\hline \multirow[t]{3}{*}{ FTIR main peaks, $\mathrm{cm}^{-1}$ (assignment) } & $3319(\mathrm{~N}-\mathrm{H}$ stretching $) 1711(\mathrm{C}=$ & ending) \\
\hline & $1628,1585(\mathrm{C}=\mathrm{N}$ stretching $)$ & $1614,1574(\mathrm{C}=\mathrm{N}$ stretching $)$ \\
\hline & 2955, 2926 (C-H stretching) & 2955, 2911 (C-H stretching) \\
\hline Fingerprint region & $885,862,847,804,759,729,611$ & $880,866,845,754,731$ \\
\hline
\end{tabular}
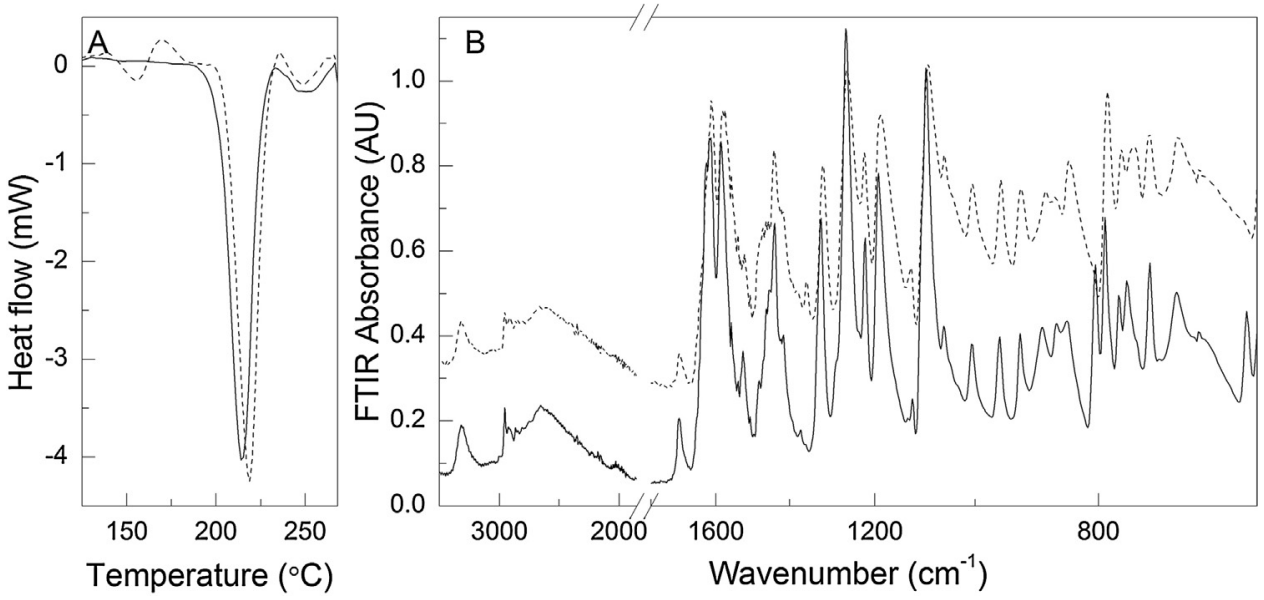

Fig. 2. (A) DSC thermograms of Form I (-) and Form II (-) of ALB. (B) ATR-FTIR spectra of Forms I (-) and II (-) of ALB in the $3700-600 \mathrm{~cm}^{-1}$ region.

to different authors [12,35], these correspond to a transition which includes the melting of Form II and its conversion into Form I.

This event is followed by an endothermic peak at $218.8^{\circ} \mathrm{C}$, which relates to the melting point of Form I [36]. These main endotherms were in agreement with the images recorded by digital microscopy when a temperature ramp was applied to samples of the solid-state forms.

In the FTIR spectra (Fig. 2B), showed slight differences between both forms. The most noticeable differences were found in the regions related to $\mathrm{C}=\mathrm{N}$ stretching $\left(1630-1570 \mathrm{~cm}^{-1}\right), \mathrm{C}-\mathrm{H}$ stretching $\left(2960-2910 \mathrm{~cm}^{-1}\right)$ and the fingerprint region $\left(900-600 \mathrm{~cm}^{-1}\right)$. These observations were in agreement with the results of Chattah et al. [13], and provided confirmation of the identity of Form I and Form II (Table 1).

However, they were considered minor and insufficient for determination of the forms in their mixtures. Therefore, another spectroscopic alternative was sought.

A priori, X-ray diffraction seemed a suitable tool, but it demonstrated to be not good enough to confirm solid-state form differences in ALB, since it provided consistent results only when coupled with DSC and TG/DTG [16,37]. Hence, the attention was focused on Raman spectroscopy.

As depicted in Fig. 3A, Forms I and II exhibited differences in their Raman spectra. Particularly, peaks at 2926 and $2900 \mathrm{~cm}^{-1}$ were observed to have different intensities in each solid-state form. The same phenomenon was observed among the pairs of peaks at 1574.8 and $1537.7 \mathrm{~cm}^{-1}$. Additionally, in the range $1639-1600 \mathrm{~cm}^{-1}$, Form I exhibited a single peak, but Form II displayed a peak and shoulder.

A peak at $1361 \mathrm{~cm}^{-1}$ was typically found in Form II while a shoulder at $1324 \mathrm{~cm}^{-1}$ was characteristic for Form I (Fig. 3B). In addition, a small peak found at $1122 \mathrm{~cm}^{-1}$ in Form I, appeared shifted to $1130 \mathrm{~cm}^{-1}$ in Form II. Further differences were observed in the region comprised between the valleys at 920 and $820 \mathrm{~cm}^{-1}$,
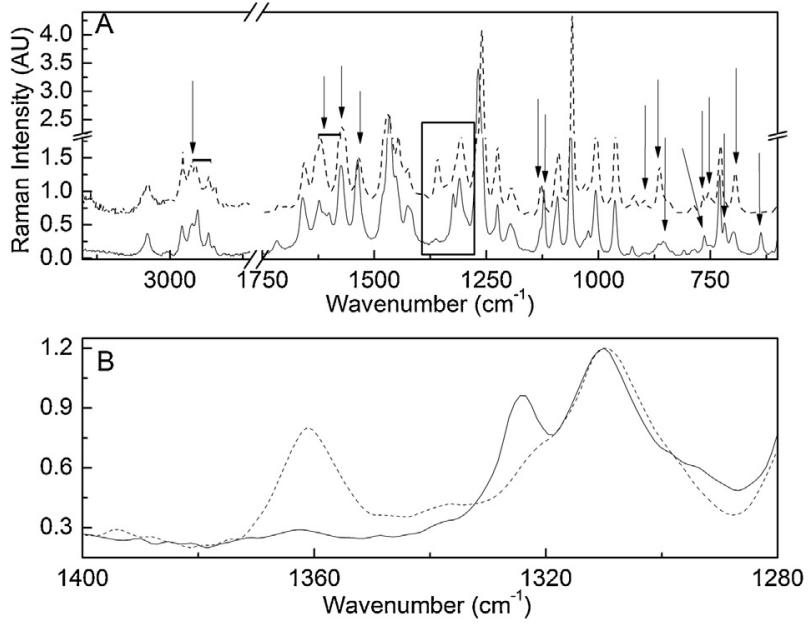

Fig. 3. (A) Raman fluorescence spectra of the solid-state forms of ALB, Form I $(-)$ and Form II (-). (B) Spectral region with useful quantitative information $\left(1396-1280 \mathrm{~cm}^{-1}\right)$.

where Form II showed two peaks at 900 and $866 \mathrm{~cm}^{-1}$, while Form I exhibited two small overlapped peaks at 866 and $855 \mathrm{~cm}^{-1}$.

On the other hand, the peaks at $769 \mathrm{~cm}^{-1}$ and $756 \mathrm{~cm}^{-1}$ were found to be typical of Form II and only one signal was found in this region of the spectrum of Form $\mathrm{I}\left(764 \mathrm{~cm}^{-1}\right)$. Finally, the peaks at $719 \mathrm{~cm}^{-1}$ and $638 \mathrm{~cm}^{-1}$ are present only in Form I and the signal at $697 \mathrm{~cm}^{-1}$ is of lower intensity in Form I than in Form II. The hypothesis that chemometrics-assisted enhancement of these minor differences in the Raman spectra (Table 2) could be useful for distinguishing among the solid state forms, encouraged the development of an analytical method to quantitate Form I in bulk drug, by coupling a chemometrics stage to the Raman spectroscopic data. 
Table 2

Main signals and differences in the Raman spectra of Forms I and II of ALB.

\begin{tabular}{llc}
\hline Raman signal $\left(\mathrm{cm}^{-1}\right)$ & Form I & Form II \\
\hline $2926-2900$ & Peaks with different height proportions \\
$1639-1600$ & Peaks & Peak and shoulder \\
$1575-1538$ & Peaks with different height proportions \\
$1361^{\mathrm{a}}$ & - & Peak \\
$1324^{\mathrm{a}}$ & Shoulder & - \\
$1309^{\mathrm{a}}$ & Peak with different size in each Form \\
$1130^{\mathrm{b}}$ & - & Peak \\
$1122^{\mathrm{b}}$ & Peak & - \\
900 & - & Small peak \\
866 & Small peak & Medium sized peak \\
855 & Small peak & - \\
769 & - & Small peak \\
764 & Small peak & - \\
756 & - & Small peak \\
719 & Peak & - \\
697 & Small peak & Medium sized peak \\
638 & Peak & - \\
\hline
\end{tabular}

a Quantitative information.

b Solid-state form-dependent peak shift.

\subsection{Development of a quantitative method for estimating crystal form content}

\subsubsection{Data acquisition and pre-processing}

In order to develop a quantitative method for the determination of the abundance of Form I (commercial form) in the bulk API, training and validation sets were prepared according to the proportions and number of replicates depicted in Table 3. The whole set of samples $(n=45)$ was measured at random in triplicate by Raman fluorescence microscopy, yielding a grand total of $135 \mathrm{spec}-$ tra. Spectra belonging to the different sets of samples were grouped and arranged as a single matrix.

In order to reduce the instrumental noise inherent to Raman spectroscopy, the data were subjected to several pre-treatments. First, the spectra were smoothed applying the Savitzky-Golay algorithm. The average of 3 measurements for each sample was taken to decrease dispersion and the mean spectra were used for further calculations.

Then, the intensity of the spectra was normalized using as reference the peak at $1307 \mathrm{~cm}^{-1}$, which holds similar intensity in both solid-state forms (Fig. 3B). Additionally, the spectra were standard normal variate (SNV) correction and finally, irregular baseline tendencies were removed by an automatic de-trending procedure [38].

\subsubsection{Multivariate calibration (PLS) method development and validation}

Once the Raman spectra were normalized, a suitable Partial Least Squares (PLS) model was developed using the Training set. First, a PRESS-minimization guided moving window of variable size variable selection strategy [39] was carried out in order to find optimal conditions for the PLS model. The so found optimal spectral region was $1396-1280 \mathrm{~cm}^{-1}$ (Fig. 3B).

Then, the optimal number of PLS factors was obtained by exploration of the cumulative explained variance plot. It was observed that a single factor explained $93.2 \%$ of the variation in the $\mathrm{X}$ axis and $69.2 \%$ in the $Y$ axis, whereas three factors accounted for $99.8 \%$ of the variation in $\mathrm{X}$ and $99.1 \%$ of the total variance in the $\mathrm{Y}$ axis. The explained variance did not suffer any significant increment by increasing the number of factors; hence, the number of factors (LV) was set at 3 (Fig. 4A).

Once the PLS parameters were established, an intensive process of model validation was carried out. First, an internal validation was carried out, by examination of the figures of merit obtained from the cross-validation procedure. As displayed in Table 4, acceptable root-mean-square deviation (RMSD, 5.6\%) and residual error during calibration (REC, 11.2\%) values were obtained. In addition, the coefficient of correlation $\left(r^{2}=0.9729\right)$ was close to 1.0 , evidencing a good fit of the PLS model to the data, and the computed selectivity ( $S E L=0.220$ ) also showed that the method is suitable for its purpose.

Furthermore, low values of the minimum detectable difference of concentration (MDDC $=1.37 \%$ ), and the limits of detection $(\mathrm{LOD}=9.4 \% \mathrm{w} / \mathrm{w})$ and quantitation ( $\mathrm{LOQ}=28.5 \% \mathrm{w} / \mathrm{w})$ suggested that the method holds wide operative range. This range results suitable for the daily work, especially because the expected abundance of Form I in the API of commercial bulk drug samples is higher than $80 \% \mathrm{w} / \mathrm{w}$

In a second step, an external validation stage was carried out by examination of the validation sets. The range and linearity of the method were evaluated by plotting the actual vs. predicted values for the Validation I set. It was observed that the elliptical joint confidence region [40] for the slope and intercept of the curve contains the point $(0,1)$. This fulfilled the test (Fig. 4B) and confirmed that the method is devoid of systematic and bias errors.

The accuracy and precision of the PLS-based method were evaluated using the Validation II set (Table 5). The former was assessed by monitoring the prediction of the contents of Form I at 3 levels $(60,70$ and $80 \% w / w)$. Finding that the recoveries were not statistically different from $100 \%$ confirmed the accuracy of the proposed method.

Table 3

Details of the training and validation samples of ALB.

\begin{tabular}{|c|c|c|c|c|c|}
\hline Sample Set & Scope & No. of Levels & Content of Form I $(\% w / w)$ & No. of Replicates & No. of Samples \\
\hline Training & Calibration & 6 & $0,20,40,60,80,100$ & 3 & 18 \\
\hline Validation I & Method performance & 5 & $10,30,50,70,90$ & 3 & 15 \\
\hline Validation II & Accuracy/Precision & 3 & $60,70,80$ & 2 & 6 \\
\hline Commercial & Method Suitability & 3 & $25,50,75$ & 2 & 6 \\
\hline Grand total & & & & & 45 \\
\hline
\end{tabular}

Table 4

Analytical summary of the calibration parameters and statistical data for the PLS determination of ALB Form I.

\begin{tabular}{|c|c|c|c|}
\hline Parameter & Value & Parameter & Value \\
\hline Spectral range $\left(\mathrm{cm}^{-1}\right)$ & $1396-1280$ & $r^{2}$ (actual vs. predicted) & 0.9729 \\
\hline Linear range $(\%, w / w)$ & $28-100$ & SEL & 0.220 \\
\hline $\mathrm{N}^{\circ}$ of PLS factors (LV) & 3 & Sensitivity (SEN) & 0.023 \\
\hline $\mathrm{N}^{\circ}$ of training samples & 18 & Analytical sensitivity $\left(\gamma, \%^{-1}, w / w\right)$ & 0.730 \\
\hline PRESS & 566.3 & $\operatorname{MDDC}(\%, w / w)$ & 1.37 \\
\hline RMSD (\%) & 5.6 & $\operatorname{LOD}(\%, w / w)$ & 9.4 \\
\hline $\operatorname{REC}(\%)$ & 11.2 & $\operatorname{LOQ}(\%, w / w)$ & 28.5 \\
\hline
\end{tabular}



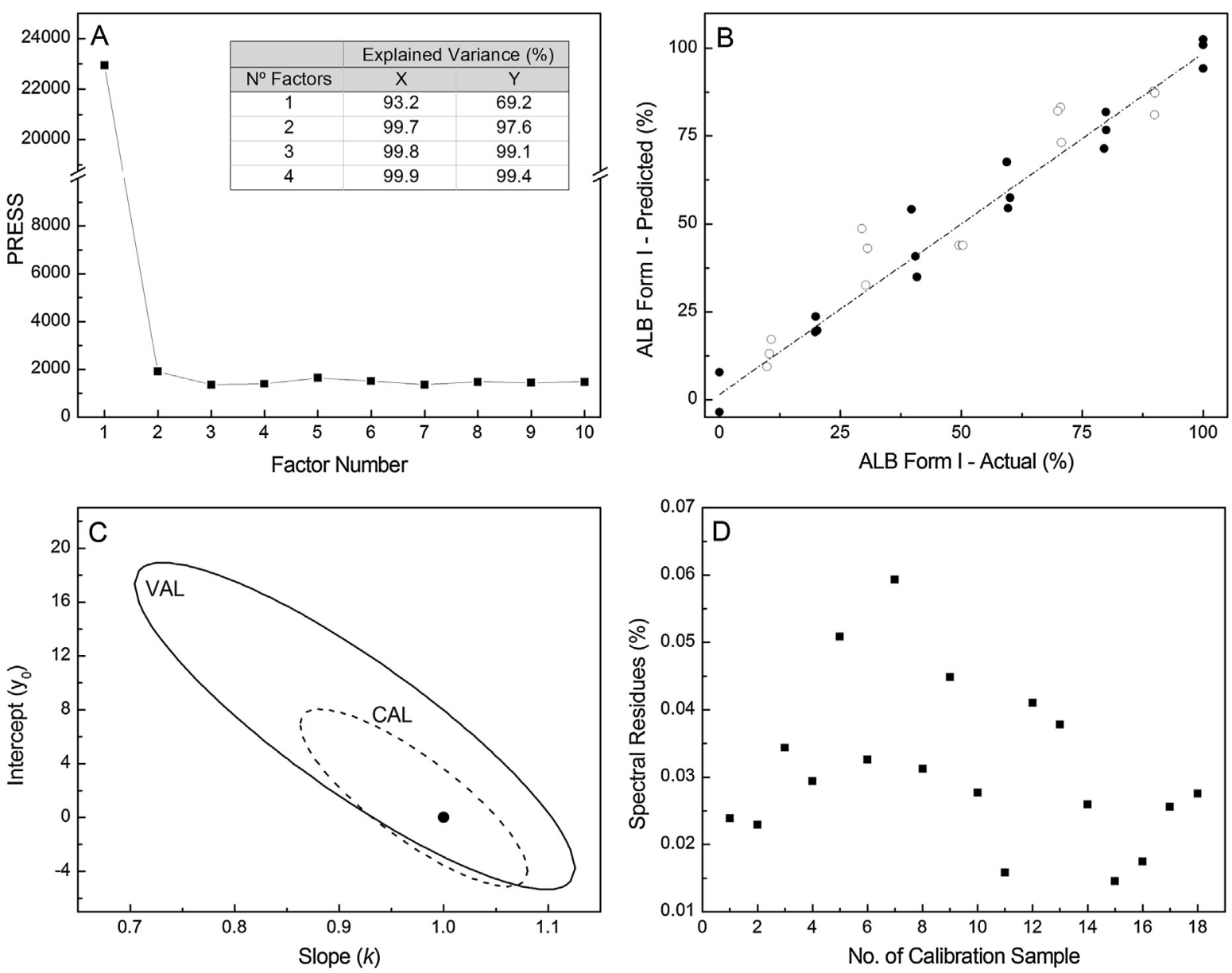

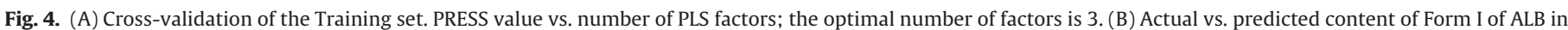

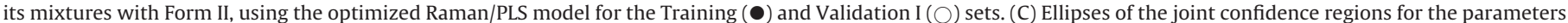
of the fitting lines for the Training and Validation I sets. (D) Distribution of the spectral residues vs. calibration sample number.

On the other hand, in order to evaluate method precision, data dispersion was monitored at the same 3 levels. It was observed that the overall standard deviation (SD, \%) was $2.83 \%$ and the relative error of the predictions (REP, 3.99\%) was lower than $10 \%$.

\subsubsection{Application. Assignment of solid-state form identity in commercial samples}

The proposed methodology was employed for the evaluation of a different lot of a market sample of ALB (Commercial set). Because this kind of samples ALB containing Form II could not be obtained, the commercial lot 2 was spiked with Form II at levels of 75, 50 and $25 \% w / w$ and their contents of Form I were determined employing the Raman-PLS method.

As exhibited in Fig. 5A, the method was able to satisfactorily predict the richness of Form I in all the spiked commercial samples. The overall recovery was almost quantitative $(94.2 \% \mathrm{w} / \mathrm{w})$ and the dispersion of the results $(6.4 \%)$ was not different from that observed during the validation procedure. Additionally, the joint confident test for the slope and intercept of the actual vs. predicted

Table 5

Linearity, accuracy and precision analysis on prediction data of the validation sets.

\begin{tabular}{|c|c|c|c|}
\hline Validation Set I (linearity) & Actual vs. predicted curve & & \\
\hline Concentration levels $(\%, w / w)$ & $10,30,50,70$ and 90 & & \\
\hline Number of samples & 15 & & \\
\hline$r^{2}$ & 0.9164 & & \\
\hline Intercept $\left(\mathrm{y}_{0}\right)$ & $6.8 \pm 4.4$ & & \\
\hline Slope $(k)$ & $0.92 \pm 0.08$ & & \\
\hline Validation Set II (accuracy and precision) & Level 1 & Level 2 & Level 3 \\
\hline Concentration $(\%, w / w)$ & 60 & 70 & 80 \\
\hline Number of samples & 2 & 2 & 2 \\
\hline \multicolumn{4}{|l|}{ Summary of statistics } \\
\hline Recovery of Form I (\%) & 104.6 & 102.2 & 98.4 \\
\hline $\mathrm{SD}(\%)$ & 0.16 & 0.48 & 0.90 \\
\hline Mean recovery (\%) & 101.7 & & \\
\hline Overall SD (\%) & 2.83 & & \\
\hline $\operatorname{REP}(\%)$ & 3.99 & & \\
\hline
\end{tabular}



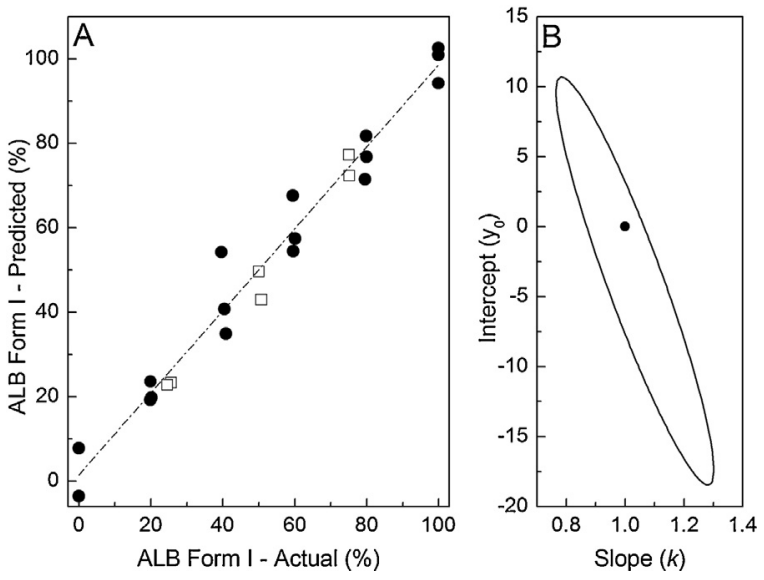

Fig. 5. (A) Actual vs. predicted content of Form I in spiked Commercial samples of ALB ( $\square$ ) and in the Training set ( ). (B) Joint confidence region for the parameters (slope and intercept) of the actual vs. predicted curve in the Commercial samples of ALB.

line adjusting the results revealed the absence of significant bias and systematic errors in the predictions (Fig. 5B).

\section{Conclusions}

Summing up, this study was aimed to develop a facile and efficient method to assess and determine the main crystal form of ALB in solid-state mixtures of its drug forms, based on an optimized quantitative multivariate model. To that end, both solid-state forms of ALB were obtained and unambiguously characterized using digital optical microscopy (with and without polarized light), thermal analysis (DSC), as well as infrared and Raman spectroscopies.

Raman spectra were acquired and a PLS model was built with the calibration samples, containing varying amounts of both forms of ALB. The optimal parameters of this multivariate model included the use of 3 PLS factors in the $1396-1280 \mathrm{~cm}^{-1}$ spectral window, on samples subjected to successive spectral pre-treatments, including smoothing, normalization, SNV correction and de-trending.

The suitability of the Raman-PLS model was assessed by an exhaustive process, comprising internal and external validation protocols. The internal cross-validation procedure furnished figures of merit that were considered satisfactory. On the other hand, the external validation was performed with the aid of two independent sets of samples (Validation I and Validation II). The method did not show any systematic or bias errors, the recovery rate was close to $100 \%$ and data dispersion was lower than $3 \%(101.7 \pm 2.8 \%)$ over a wide range. Additionally, a set of spiked commercial samples was evaluated, evidencing that the method consistently provides reliable results.

In conclusion, the proposed PLS-Raman method is a suitable tool, able to assess the abundance of the solid-state form I in ALB bulk drug. This non-destructive determination requires minimal sample manipulation; it also features low processing time, does not use polluting solvents and is devoid of production of hazardous waste, thus complying with many of the principles of green analytical chemistry. The method, which is a valuable alternative for assigning the solid-state identity and quantitating the main solidstate form in ALB bulk drug, is amenable for routine use in the pharmaceutical quality control laboratory.

\section{Acknowledgements}

The authors gratefully acknowledge Consejo Nacional de Investigaciones Científicas y Técnicas (CONICET, PIP 2011-0471), Agencia Nacional de Promoción de Ciencia y Tecnología (ANPCyT, PICT
2014-005), Secretaría de Ciencia Tecnología e Innovación (SECTeI, Project 2010-085-11) and Secretaría de Ciencia y Tecnología de la UNR (SECyT-UNR, Project BIO457) for financial support. NLC is also thankful to CONICET for her fellowship.

\section{References}

[1] Goodman \& Gilman's the Pharmacological Basis of Therapeutics, in: L.L. Brunton, J.S. Lazo, K.L. Parker (Eds.), 11 st ed., McGraw-Hill, New York, USA, 2006, p. 1079.

[2] B. Dembele, Y.I. Coulibaly, H. Dolo, S. Konate, S.Y. Coulibaly, D. Sanogo, L. Soumaoro, M.E. Coulibaly, S.S. Doumbia, A.A. Diallo, S.F. Traore, A.D. Keita, M.P. Fay, T.B. Nutman, A.D. Klion, Use of high-dose, twice-yearly albendazole and ivermectin to suppress Wuchereria bancrofti microfilarial levels, Clin. Infect. Dis. 51 (2010) 1229-1235

[3] A. Bosco, L. Rinaldi, V. Salamina, M. Santaniello, M.E. Morgoglione, I. Guariglia, G. Cappelli, A. Scala, G. Cringoli, Field trial on the efficacy of albendazole micronised (single and double treatment) against Dicrocoelium dendriticum in naturally infected sheep: a new strategy for the control of dicrocoeliosis, Small Rumin. Res. 126 (S1) (2015) 2-5.

[4] M. Matos, A.M. Alho, S.P. Owen, T. Nunes, L. Madeira de Carvalho, Parasite control practices and public perception of parasitic diseases: a survey of dog and cat owners, Prevent. Vet. Med. 122 (2015) 174-180.

[5] World Health Organization, WHO model list of essential medicines, 19th List, 2015. Available at http://www.who.int/selection_medicines/committees/ expert/20/EML_\%202015_FINAL_amended_AUG2015.pdf?ua=1 (accessed 29.04.16).

[6] The Indian Pharmacopoeia Commission, Ghaziabad, Indian Pharmacopoeia, 2, 2007, pp. 74-75.

[7] British Pharmacopoeia 2010 on CD, The Stationery Office, London, UK, 2010

[8] The United States Pharmacopeial Convention, The United States Pharmacopeia and The National Formulary (USP32/NF27), Rockville, MD, USA 2008, p. 1435.

[9] European Pharmacopoeia, 7th ed., Council of Europe Strasbourg, France, 2010 pp. 1335-1336.

[10] Polymorphism in Pharmaceutical Solids, in: H.G. Brittain (Ed.), Marcel Dekker New York, USA, 1999, pp. 1-31.

[11] S.R. Vippagunta, H.G. Brittain, D.J.W. Grant, Crystalline solids, Adv. Drug Deliv. Rev, 48 (2001) 3-26.

[12] M.B. Pranzo, D. Cruickshank, M. Coruzzi, M.R. Caira, R. Bettini, Enantiotropically related albendazole solid-state forms, J. Pharm. Sci. 99 (2010) 3731-3742

[13] A.K. Chattah, R. Zhang, K.H. Mroue, L.Y. Pfund, M.R. Longhi, A. Ramamoorthy, C. Garnero, Investigating albendazole desmotropes by solid-state NMR spectroscopy, Mol. Pharm. 12 (2015) 731-741.

[14] J. Elguero, Solid-state formism and desmotropy in heterocyclic crystal structures, Cryst. Growth Des. 11 (2011) 4731-4738.

[15] R. Hilfiker, Polymorphism: in the Pharmaceutical Industry, Wiley-VCH, Weinheim, Germany, 2006, pp. 144-148.

[16] N.C. Tavares Cavalcanti, G.D. Sousa, M.A. Maciel Tabosa, J.L. Soares Sobrinho, L. Bastos Leal, D. Pereira de Santana, Assay and physicochemical characterization of the antiparasitic albendazole, Braz. J. Pharm. Sci. 48 (2012) 281-290.

[17] K. Lixandrao, F. Ferreira, Structural characterization of albendazole with the use of X-ray diffraction, Acta Cryst. A 70 (2014) C1808.

[18] R.L. Roque Flores, Caracterização físico-química e desenvolvimento de metodologia para avaliação da dissolução intrínseca de albendazol e mebendazol, Master Thesis, University of Sao Paulo, Brazil, 2011, Available at www.teses.usp.br/teses/disponiveis/9/9139/tde-16042013-120458/publico/ Mestrado_Roxana_Flores.pdf (accessed 29.04.16).

[19] R. Kalaiselvan, G.P. Mohanta, P.K. Manna, R. Manavalan, Studies on mechanism of enhanced dissolution of albendazole solid dispersions with crystalline carriers, Indian J. Pharm. Sci. 68 (2006) 599-607.

[20] C.E.P. Malan, M.M. De Villiers, A.P. Lötter, Evaluation of compatibility of table excipients with albendazole and closantel using DSC and HPLC, Drug Dev. Ind. Pharm. 23 (1997) 533-537.

[21] F.K. Alanazi, M. El-Badry, M.O. Ahmed, I.A. Alsarra, Improvement of albendazole dissolution by preparing microparticles using spray-drying technique, Scientia Pharm. 75 (2007) 63-79.

[22] R.A. Rane, S. Naithani, R.D. Natikar, S. Yerma, Sudhakar, A process for preparation of albendazole, WO Patent 070069, 2012.

[23] M. Vogt, K. Kunath, J.B. Dressman, Dissolution improvement of four poorly water soluble drugs by cogrinding with commonly used excipients, Eur. J. Pharm. Biopharm. 68 (2008) 330-337.

[24] K. Daniel-Mwambete, S. Torrado, C. Cuesta-Bandera, F. Ponce-Gordo, J.J Torrado, The effect of solubilization on the oral bioavailability of three benzimidazole carbamate drugs, Int. J. Pharm. 272 (2004) 29-36.

[25] N. Kohri, Y. Yamayoshi, H. Xin, K. Iseki, N. Sato, S. Todo, K. Miyazaki, Improving the oral bioavailability of albendazole in rabbits by the solid dispersion technique, J. Pharm. Pharmacol. 51 (1999) 159-164.

[26] M. Lindenberg, S. Kopp, J.B. Dressman, Classification of orally administered drugs on the world health organization model list of essential medicines according to the biopharmaceutics classification system, Eur. J. Pharm. Biopharm. 58 (2004) 265-278. 
[27] Center for Drug Evaluation and Research, Guidance for Industry; ANDAs: Pharmaceutical Solid Solid-State Forms: Chemistry, Manufacturing, and Controls Information, Food and Drug Administration, 2007.

[28] GlaxoSmithKline Pharmaceuticals Limited, Annual report for the year ended 31st December 2011, Opening up a new world, p. 11, available at: http://indiapharma.gsk.com/media/711805/annual-report-2011.pdf (accessed 29.04.16).

[29] J.M. Shaver, Chemometrics for Raman spectroscopy, in: I.R. Lewis, H. Edward (Eds.), Handbook of Raman Spectroscopy: From the Research Laboratory to the Process Line, Marcel Dekker, New York, USA, 2001 (Chapter 7).

[30] F. de Souza Lins Borba, R.S. Honorato, A. de Juan, Use of Raman spectroscopy and chemometrics to distinguish blue ballpoint pen inks, Forensic Sci. Int. 249 (2015) 73-82

[31] N.L. Calvo, R.M. Maggio, T.S. Kaufman, A PCA-based chemometrics-assisted ATR-FTIR approach for the classification of polymorphs of cimetidine. Application to physical mixtures and tablets, J. Pharm. Biomed. Anal. 107 (2015) 419-425.

[32] N.L. Calvo, R.M. Maggio, T.S. Kaufman, A dynamic thermal

ATR-FTIR/chemometrics approach to the analysis of polymorphic interconversions. Cimetidine as a model drug, J. Pharm. Biomed. Anal. 92 (2014) 90-97.

[33] N.L. Calvo, R.M. Maggio, T.S. Kaufman, Mebendazole crystal forms in tablet formulations. An ATR-FTIR/chemometrics approach to polymorph assignment, J. Pharm. Biomed. Anal. 122 (2016) 157-165.
[34] J.R. Moyano, J. Liró, J.I. Pérez, M.J. Arias, P.J. Sánchez-Soto, Thermal analysis of albendazole investigated by HSM, DSC and FTIR, in: A. Méndez-Vilas (Ed.), Microscopy: Advances in Scientific Research and Education, Formatex, Madrid, Spain, 2014, available at http://www.microscopy6book.org/vol2.html (accessed 29.04.16).

[35] J. Liró, Estudio del polimorfismo en albendazol mediante análisis térmico y espectroscopía de infrarrojos, Master Thesis, University of Sevilla, Spain, 2008.

[36] M.L. López García, Potenciación de la actividad antihelmíntica del albendazol mediante modificaciones en su biodisponibilidad y metabolismo, Ph. D. Thesis, Universidad Complutense de Madrid, Spain, 1996, http://eprints.ucm. es/tesis/19911996/D/1/AD1023701.pdf, (accessed 29.04.16).

[37] S. Storpirtis, J.E. Gonçalves, C. Chiann, M.N. Gai, Ciências farmacêuticas: biofarmacotécnica, Rio de Janeiro, Brazil, 2009.

[38] R.J. Barnes, M.S. Dhanoa, S.J. Lister, Standard normal variate transformation and de-trending of near-infrared diffuse reflectance spectra, Appl. Spectrosc. 43 (1989) $772-777$

[39] R.M. Maggio, P.M. Castellano, T.S. Kaufman, A multivariate approach for the simultaneous determination of losartan potassium and hydrochlorothiazide in a combined pharmaceutical tablet formulation, Anal. Bioanal. Chem. 391 (2008) 2949-2955.

[40] J.S. Hunter, Calibration and the straight line: current statistical practices, J. Assoc. Anal. Chem. 64 (1981) 574-583. 